\title{
Mechanical analysis and toughening mechanisms of a multiphase recycled CFRP
}

\author{
Soraia Pimenta ${ }^{\mathrm{a}, *}$, Silvestre T. Pinho ${ }^{\mathrm{a}}$, Paul Robinson ${ }^{\mathrm{a}}$, Kok H. Wong ${ }^{\mathrm{b}}$, Stephen J. \\ Pickering ${ }^{\mathrm{b}}$ \\ ${ }^{a}$ The Composites Centre, Department of Aeronautics, South Kensington Campus, Imperial College \\ London. London SW7 2AZ, United Kingdom \\ ${ }^{b}$ Division of Materials, Mechanics and Structures, Faculty of Engineering, The University of \\ Nottingham, University Park, Nottingham NG7 2RD, UK
}

\begin{abstract}
The mechanical response of a recycled CFRP is investigated experimentally. A complex multiscale microstructure is revealed, with both dispersed fibres (with fractured sections) and fibre bundles. The specific properties of the recyclate compare favourably with those of aluminium and glass-fibre composites. Micromechanical studies show that tensile failure follows the pre-existing fractured-sections on the dispersed fibres, while compressive failure occurs by shear-banding. Fracture toughness measurements coupled with SEM evidence how bundles considerably toughen the composite by complex failure mechanisms. This analysis can guide the optimisation of recycling processes and support the development of design methods for recycled CFRP; it also provides insight on the mechanical response of other multiphase short-fibre reinforced materials. Keywords: A. Recycling, A. Multiscale composites, B. Mechanical properties, B. Fracture toughness, C. Damage mechanics.
\end{abstract}

\section{Introduction}

Both environmental and economical reasons have driven the development of recycling routes for Carbon Fibre Reinforced Polymer (CFRP) waste [1]. In this paper, the mechanical behaviour of a state-of-the-art recycled ( $\mathrm{r}-$ ) composite is investigated.

Generally, recycling a thermoset composite comprises two steps. Firstly, the Carbon Fibres (CFs) are reclaimed from the virgin (v-) composite, using either a thermal [2-4] or chemical $[5,6]$ process to degrade the matrix; this generally outputs recycled fibres with

\footnotetext{
${ }^{*}$ Corresponding author.

Email address: soraia.pimenta@imperial.ac.uk (Soraia Pimenta)
}

Pimenta S, Pinho ST, Robinson P, Wong KH, Pickering SJ (2010). Mechanical analysis and toughening mechanisms of a multiphase recycled CFRP. Composites Science and Technology 70, 1713-1725. DOI : 10.1016/j.compscitech.2010.06.017 
little (under 10\%) mechanical degradation [7]. The second step is the reimpregnation of these rCFs with new resin to manufacture a recycled composite; several methods are documented [8-10], but one of the most widely used is the papermaking of intermediate non-woven mats, followed by their compression moulding with resin films [10-13].

Wong et al. [11] manufactured a rCFRP particularly similar to the one analysed in this paper (only the epoxy resin formulation used for reimpregnation was different). After pyrolysis, the rCFs comprised both dispersed-fibres and fibre-bundles (held together by residual virgin matrix or char); due to a fibre-disentanglement stage during the papermaking process, only few bundles remained present in the non-woven mats. In addition, it was shown that considerable fibre-fracture occurred during compression moulding, due to the high pressures applied; this would have left most of the fibres shorter than the critical length. Nevertheless, a good adhesion was found between the longer fibres and the epoxy matrix.

The specific mechanical properties of many rCFRPs compare favourably with those of conventional materials, such as aluminium and virgin glass-fibre composites (Fig. 1) [9, 10, 12]. Nevertheless, the architecture of rCFRPs can be unique and extremely complex (e.g. with fibre-bundles and a wide fibre length distribution [11]), so it is essential to investigate their mechanical response with a deeper detail [14]. This will provide informed guidance for recyclers towards materials with optimal structural performance; moreover, it will set the scenario for developing design methods for rCFRPs, which are essential to establish a market of structural applications for these materials.

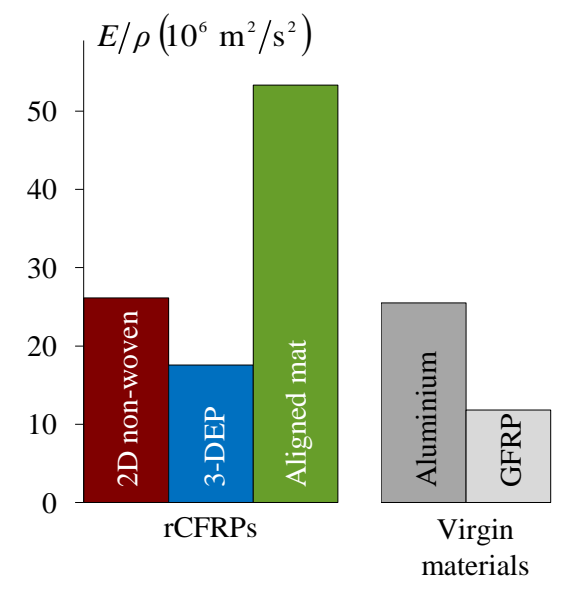

(a) Specific stiffness.

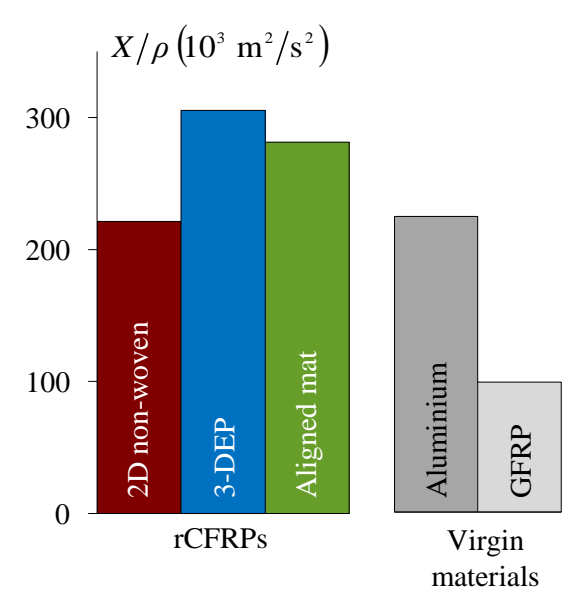

(b) Specific strength.

Figure 1: Mechanical properties of rCFRPs vs. conventional structural virgin materials. The rCFRPs shown were produced from 2D non-woven mats [12], 3-DEP process [9], and aligned mats [10]. 
This paper presents an experimental investigation on the mechanical response of a rCFRP, including: (i) the analysis of its microstructure, (ii) the characterisation of mechanical properties, (iii) the measurement of fracture toughnesses, and (iv) the micromechanical analysis of failure and toughening mechanisms. This study confirms that rCFRPs are a competitive alternative to conventional structural materials. It also discusses the relations amongst (a) the recycling process, (b) the multiscale microstructure, and (c) the micromechanics of damage.

The paper is organised as follows: Section 2 identifies the rCFRP studied; Section 3 describes the experimental procedures undertaken, being the results presented in Section 4. Section 5 discusses several aspects of the mechanical response of the recyclate, and the main conclusions are summarised in Section 6.

\section{Material}

The material under investigation is a rCFRP. The precursor was a T300-epoxy woven pre-preg (Boeing's manufacturing scrap), from which the fibres were recovered by pyrolysis at Recycled Carbon Fibre Ltd [2].

The recycled composite was manufactured at the University of Nottingham. The recycled woven fabric was chopped (at Recycled Carbon Fibre) so as to produce fibres with an average length of $12 \mathrm{~mm}$, and converted in $110 \mathrm{gsm} \mathrm{rCF}$ non-woven mats by a wet papermaking process (at Technical Fibre Products Ltd.). The mats were subsequently compression moulded at 7MPa with 300gsm ACG XMTM 257 epoxy films, resulting into plates with a nominal fibre volume content of $V^{\mathrm{f}} \approx 30 \%$ and a thickness of $t \approx 2.5 \mathrm{~mm}$. A comprehensive description of a similar manufacturing process is given elsewhere [11].

Table 1 characterises both the v- and the r-CFs. The diameters $\left(\phi^{\mathrm{f}}\right)$, Young's moduli $\left(E^{\mathrm{f}}\right)$ and fibre tensile strengths $\left(X_{\mathrm{T}}^{\mathrm{f}}\right)$ were measured at the University of Nottingham [11]; the fibre-epoxy interfacial shear strengths $\left(S_{\mathrm{IF}}\right)$ were measured at Imperial College London using a Single-Fibre Pull-Out (SFPO) setup described elsewhere [15]. The increase of fibre diameter after the recycling process was confirmed to be statistical significant (p-value of $5.1 \%$ in a unilateral t-test); it can be justified by the presence of a layer of residual matrix or char on the surface of some recycled fibres.

The rCFRP plates analysed had a quasi random planar short-fibre architecture, with a preferred fibre direction induced during mat production [11]; hereafter, this direction is referred as longitudinal or direction 1 , while its in-plane normal is the transverse or direction 2; direction 3 is the through-the-thickness direction. The second 
Table 1: Properties of virgin and recycled carbon-fibres.

\begin{tabular}{lcccc}
\hline \hline \multicolumn{1}{c}{ Type of CF } & $\phi^{\mathrm{f}}(\mu \mathrm{m})^{[11]}$ & $E^{\mathrm{f}}(\mathrm{GPa})^{[11]}$ & $X_{\mathrm{T}}^{\mathrm{f}}(\mathrm{GPa})^{[11]}$ & $S_{\mathrm{IF}}(\mathrm{MPa})$ \\
\hline virgin $(\mathrm{v}-)$ & 7.03 & 227.80 & 4.24 & 83.3 \\
recycled $(\mathrm{r}-)$ & 7.20 & 217.79 & 4.16 & 86.9 \\
Relative difference & $+2.4 \%$ & $-4.4 \%$ & $-1.9 \%$ & $+4.3 \%$ \\
\hline \hline
\end{tabular}

order orientation tensor $[16,17]$ for this recycled composite can be estimated [12] as:

$$
\left\{\begin{array}{l}
a_{11} \\
a_{22} \\
a_{33}
\end{array}\right\} \approx\left\{\begin{array}{l}
0.65 \\
0.30 \\
0.05
\end{array}\right\}
$$

\section{Experimental procedures}

\subsection{Analysis of microstructure}

The microstructure of the rCFRP was studied at Imperial College London through Optical Microscopy (OM) of the three orthogonal plate sections (material planes 1-2, 1-3 and 2-3). The fibre and void volume-contents were measured in 8 through-thethickness sections (total area of $16 \mathrm{~mm}^{2}$ ), using the UTHSCSA Image Tool [18].

\subsection{Standard mechanical characterisation}

The mechanical properties of the rCFRP for in-plane tension, compression and shear (subscripts T, C and S, respectively) were measured along the two principal material directions (superscripts 1 and 2), at Imperial College London. Table 2 defines the test standards, specimen nominal geometries and displacement rates; for each test case, at least 4 specimens were tested. All specimens were end-tabbed and equipped with strain gauges: for tensile specimens, only the front faces were instrumented (after confirming that bending was negligible, by using an extra gauge on the back face of the first specimen tested); for the compression and shear tests, each face of the specimens was instrumented, so results were corrected for spurious bending (in $E_{\mathrm{C}}$ and $X_{\mathrm{C}}$ ) and torsion (in $G^{12}$ and $S^{12}$ ).

\subsection{Fracture toughness measurements}

\subsubsection{Tensile mode}

The tensile fracture toughness $\mathcal{G}_{\mathrm{T}}$ - energy required to propagate a tensile crack over a unit area - of the rCFRP was measured at Imperial College London using Compact Tension (CT) testing [22]. 
The specimens (nominal geometry in Figure 2(a)) were cut with a diamond wet saw. The holes were opened using a steel drill, and then finished with a diamond drill. The pre-crack ( $a_{0} \approx 18 \mathrm{~mm}$ long and approximately $0.6 \mathrm{~mm}$ wide) was cut with a wire saw, and sharpened with a surgical blade by sawing action. A $1 \mathrm{~mm}$ scale was drawn on the specimens, ahead of the pre-crack.

Before testing, each specimen was equipped with an extensometer fixed on two slots on its left edge (nominal opening of $46 \mathrm{~mm}$, Figure 2(a)). The load was applied through continuous displacement control of the loading pins, at $0.5 \mathrm{~mm} / \mathrm{min}$. Both the load $P$ and the opening of the extensometer $d_{\text {extens }}$ were recorded during the test. Four specimens for each material direction (1 and 2) were tested.

The data reduction was based on FE modelling of the test [22], using the elastic properties previously measured for the material (Table 4 in Section 4.2). For each experimental data point $\left(d_{\text {extens }}, P\right)$ within a crack growth of $\Delta a \in[0 ; 25 \mathrm{~mm}]$, the local fracture toughness $\mathcal{G}_{\mathrm{T}}$ was obtained by:

1. Calculating the experimental compliance, using the displacement read by the

Table 2: Specifications for the standard mechanical characterisation.

\begin{tabular}{|c|c|c|c|}
\hline Test case & $\begin{array}{c}\text { Gauge length } \\
(\mathrm{mm})\end{array}$ & $\begin{array}{c}\text { Gauge width } \\
(\mathrm{mm})\end{array}$ & $\begin{array}{l}\text { Disp. rate } \\
(\mathrm{mm} / \mathrm{min})\end{array}$ \\
\hline T1, T2: ASTM 3039 ${ }^{[19]}$ & 70 & 25 & 1.0 \\
\hline C1, C2: ICSTM ${ }^{[20]}$ & 7 & 19 & 1.0 \\
\hline S12: ASTM 5379 $9^{[21]}$ & 12 & 12 & 0.5 \\
\hline
\end{tabular}

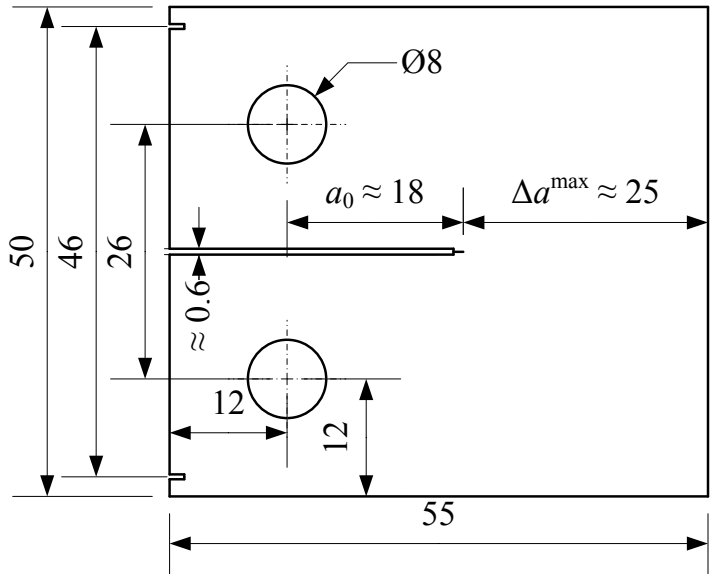

(a) CT specimen.

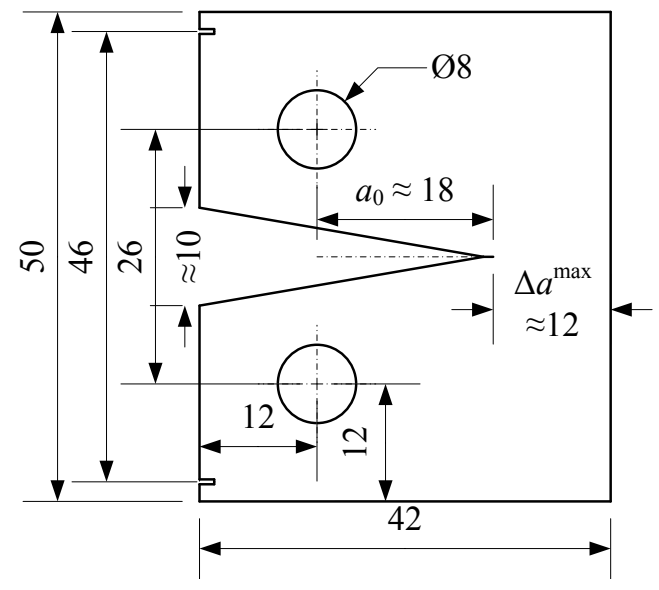

(b) CC specimen.

Figure 2: Nominal geometry of the fracture toughness specimens (dimensions in mm). 
extensometer, $C_{\text {extens }}=d_{\text {extens }} / P$;

2. Using the specimen thickness $(t)$ and spline interpolation of FE data around the previously-calculated $C_{\text {extens }}$, computing (i) the displacement at the loading pins $d$, (ii) the crack growth $\Delta a$ and (iii) the unit-load \& unit-thickness J-integral $J_{t=1}^{P=1}$;

3. Calculating the energy release rate $G_{\mathrm{T}}$ as

$$
G_{\mathrm{T}}=J_{t=1}^{P=1} \cdot\left(\frac{P}{t}\right)^{2}
$$

which coincides with the local fracture toughness of the material $\left(\mathcal{G}_{\mathrm{T}}\right)$ when crack propagation occurred at the load $P$.

Damage onset was considered to take place at a $1 \%$ increase in the specimen compliance; after initiation, the crack propagated in a stick-slip mode. A spurious transient (during $\approx 4 \mathrm{~s}$ ) decrease in compliance was noticed after most crack jumps; this was likely caused by a visco-elastic response of the material, due to the high energy released during each jump; the results were corrected by extrapolating the linear response observed after each spurious transient period.

\subsubsection{Compressive mode}

The compressive fracture toughness for initiation along the longitudinal direction,

$\mathcal{G}_{\mathrm{C}}^{1, \mathrm{i}}$, was measured using Compact Compression (CC) testing (Figure 2(b)), following similar procedures to those just described for the CT tests (Section 3.3.1).

For each specimen, a good correlation was found between (i) the visual detection of onset of crack propagation and (ii) the onset of a kink in the load $P$ vs. displacement $d_{\text {extens }}$ curve. This latter feature (highlighted in the second derivative $\left(\delta d_{\text {extens }}^{2} / \delta P^{2}\right)$ ) was therefore used to determine the load $P$ for damage initiation, and subsequently introduced on equation 1 for $\mathcal{G}_{\mathrm{C}}^{1, \mathrm{i}}$ calculation.

\subsection{Investigation of failure and toughening mechanisms}

The failure and toughening mechanisms of the rCFRP were investigated at Imperial College London through (i) post-mortem Scanning Electron Microscopy (SEM) of specimens from Sections 3.2 and 3.3, and (ii) OM of specifically designed specimens (Fig. 3); these are referred hereafter as $\mu \mathrm{T}$ and $\mu \mathrm{C}$, respectively for tension and compression. 
Stable propagation of tensile cracks was observed at the in-plane surface of $\mu \mathrm{T}$ specimens, while loaded; the compressive damage was observed at cross-sections of postmortem $\mu \mathrm{C}$ specimens. Both directions 1 and 2 were investigated.

\section{Results}

\subsection{Microstructure}

The volume-fractions of each phase in the rCFRP are shown in Table 3. The main microstructural features identified are:

- Individual fibres within the matrix, forming a dispersed-phase (Fig. 4(a)); fibrelength was greatly variable;

- Fibre-bundles, up to $1 \mathrm{~mm}$ thick and $30 \mathrm{~mm}$ long (Fig. 4(a)); these originated from tows in the virgin composite that, after pyrolysis, remained held together by residual virgin-matrix or pyrolytic-char [11];

- Fractured fibre-sections within the dispersed-fibres, in untested material (Fig. 4(b)). This fibre fracture occurred due to the high pressures applied during compression moulding (as mentioned in Section 2 [11]), mainly due to fibre-fibre interaction [23];

- Through-the-thickness fibre waviness, noticeable in Fig. 4(c) by the discontinuous visibility of the central bundle (implying it follows a wave in and out of the micrograph plane, a common feature in SFRPs [23]);

- Quasi-planar fibre orientation, evident by comparing Fig. 4(a) and Fig. 4(d);

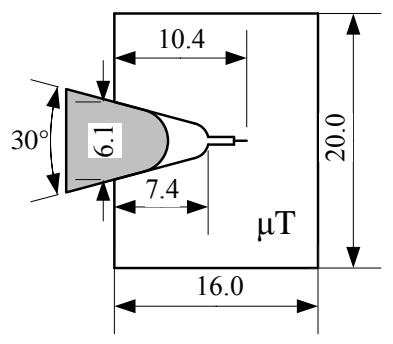

(a) Specimen geometries.

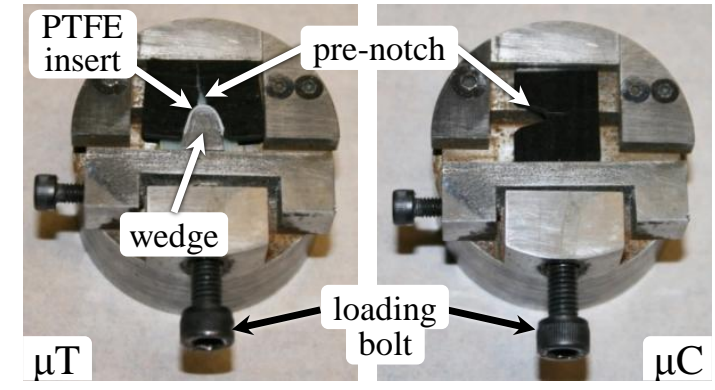

(b) Test setups.

Figure 3: $\mu \mathrm{T}$ and $\mu \mathrm{C}$ tests for investigation of failure and toughening mechanisms. 
Table 3: Volume content of the rCFRP phases.

\begin{tabular}{cc}
\hline \hline Phase & Volume content $(\%)$ \\
\hline Fibres, $V^{\mathrm{f}}$ & 27 \\
Matrix, $V^{\mathrm{m}}$ & 66 \\
Voids, $V^{\mathrm{v}}$ & 7 \\
\hline \hline
\end{tabular}

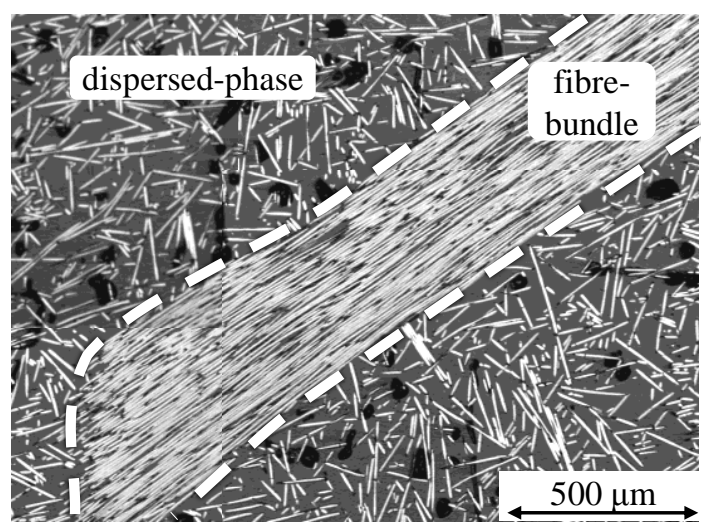

(a) In-plane view.

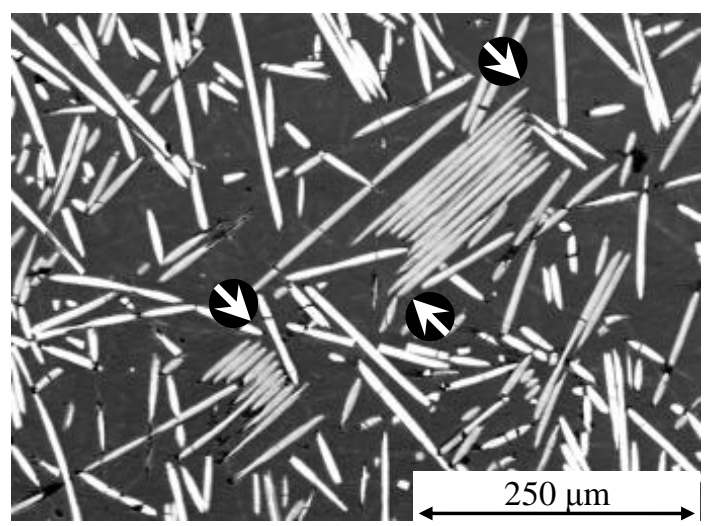

(c) Through-the-thickness waviness.

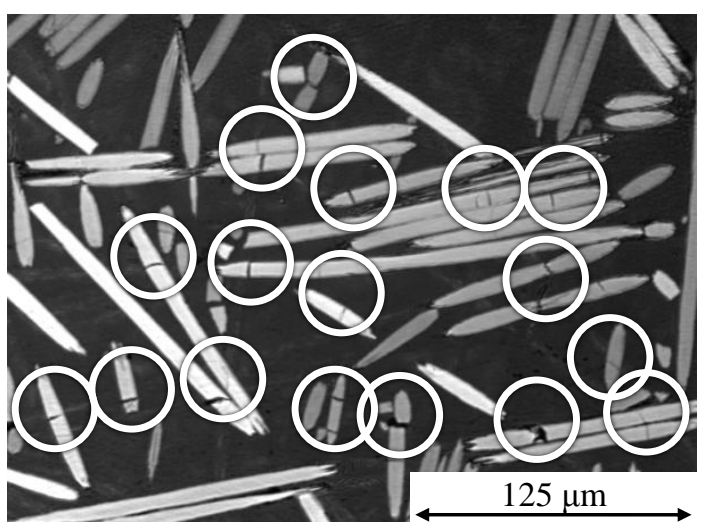

(b) Fractured fibre sections.

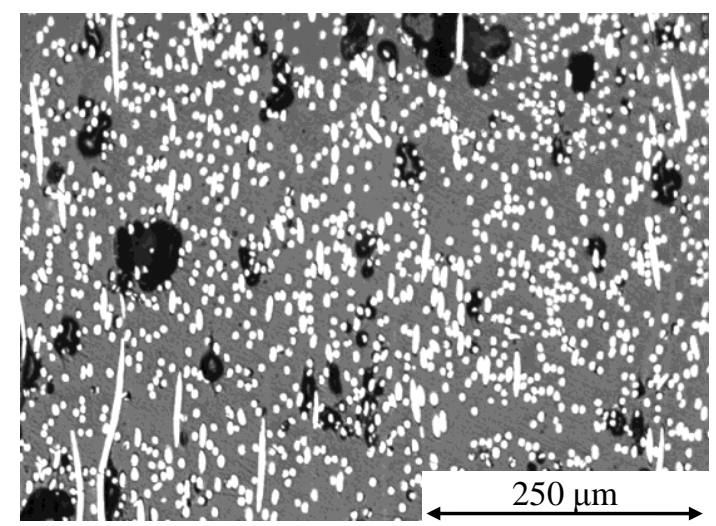

(d) Through-the-thickness view.

Figure 4: Microstructural features in the rCFRP. 
- Presence of voids, typically up to $50 \mu \mathrm{m}$ large (Fig. 4(d)); these were randomly dispersed within the matrix, with no preferential location, shape or alignment.

\subsection{Mechanical properties}

The mechanical properties obtained from the standard characterisation tests are presented in Tables 4 to 6 ; since most properties were calculated from samples with 4 specimens only, the Coefficients of Variation $(\mathrm{CoV})$ are provided as coarse indicators of the variability of the population. Typical stress vs. strain curves are shown in Fig. 5, and typical failure modes in Fig. 6.

The rCFRP responded linearly under tension, and non-linearly under compression and shear. The longitudinal strength and stiffness were higher than the transverse ones, and the material was notably stronger and more ductile in compression than tension.

The tensile specimens failed by planar brittle cracking; the failure path was parallel to the through-the-thickness direction, but irregular and curved within the 1-2 plane (especially for the longitudinal specimens, Fig. 6(a) vs. Fig. 6(b)). Under compression, the rCFRP failed by forming two rough failure surfaces, angled in the through-thethickness direction (at $\beta \approx 50^{\circ}$ to $55^{\circ}$, Fig. 6(c)). The shear specimens failed by tensile cracking, with initiation at the notch tip and planar propagation at $45^{\circ}$ (Fig. $6(\mathrm{~d})$ ).

\subsection{Tensile fracture toughness}

The CT specimens failed in a stick-slip mode (Fig. 7). All load $(P)$ vs. pindisplacement $(d)$ and energy release rate $\left(G_{\mathrm{T}}\right)$ vs. crack growth $(\Delta a)$ curves are shown in

Table 4: Elastic properties of the rCFRP.

\begin{tabular}{ccccccc}
\hline \hline Property & $E_{\mathrm{T}}^{1}(\mathrm{GPa})$ & $E_{\mathrm{T}}^{2}(\mathrm{GPa})$ & $E_{\mathrm{C}}^{1}(\mathrm{GPa})$ & $E_{\mathrm{C}}^{2}(\mathrm{GPa})$ & $G^{12}(\mathrm{GPa})$ & $\nu^{12}$ \\
\hline Average & 28.1 & 16.0 & 25.4 & 15.7 & 7.0 & 0.42 \\
$\mathrm{CoV}$ & $5.0 \%$ & $3.2 \%$ & $1.8 \%$ & $3.3 \%$ & $4.8 \%$ & $2.1 \%$ \\
\hline \hline
\end{tabular}

Table 5: Failure strengths of the rCFRP.

\begin{tabular}{cccccc}
\hline \hline Property & $X_{\mathrm{T}}^{1}(\mathrm{MPa})$ & $X_{\mathrm{T}}^{2}(\mathrm{MPa})$ & $X_{\mathrm{C}}^{1}(\mathrm{MPa})$ & $X_{\mathrm{C}}^{2}(\mathrm{MPa})$ & $S^{12}(\mathrm{MPa})$ \\
\hline Average & 194.5 & 117.0 & 358.3 & 285.0 & 139.7 \\
$\mathrm{CoV}$ & $7.4 \%$ & $11.2 \%$ & $3.0 \%$ & $2.3 \%$ & $6.8 \%$ \\
\hline \hline
\end{tabular}

Table 6: Extensions at failure of the rCFRP.

\begin{tabular}{cccccc}
\hline \hline Property & $e_{\mathrm{T}}^{1}(\%)$ & $e_{\mathrm{T}}^{2}(\%)$ & $e_{\mathrm{C}}^{1}(\%)$ & $e_{\mathrm{C}}^{2}(\%)$ & $g^{12}(\%)$ \\
\hline Average & 0.71 & 0.76 & 1.76 & 2.71 & 2.37 \\
$\mathrm{CoV}$ & $7.2 \%$ & $13.9 \%$ & $3.5 \%$ & $13.8 \%$ & $7.36 \%$ \\
\hline \hline
\end{tabular}




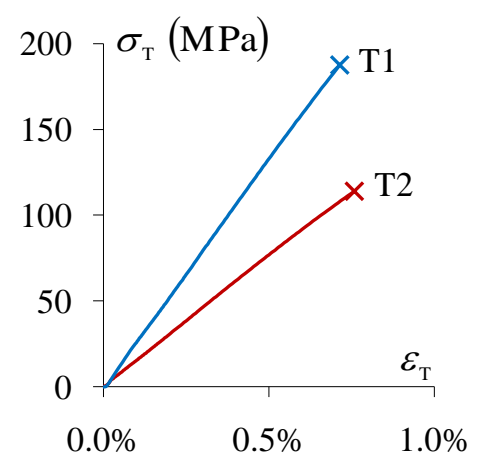

(a) Tension.

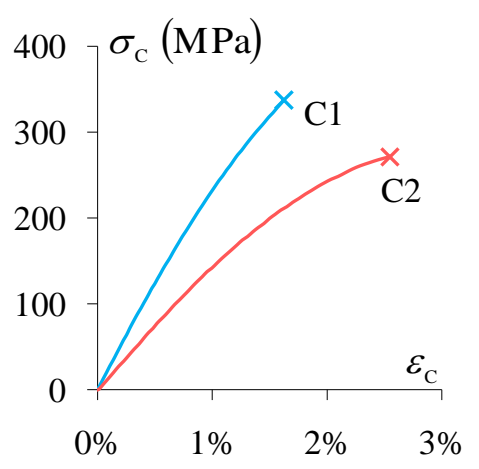

(b) Compression.

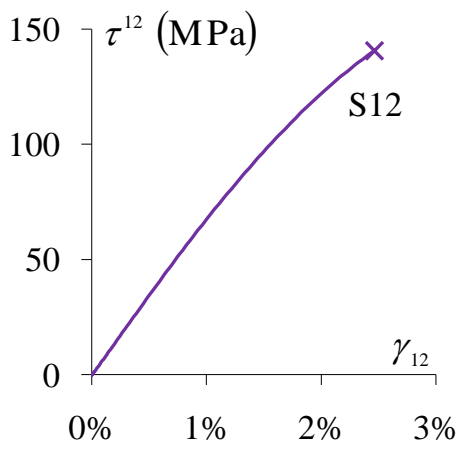

(c) In-plane shear.

Figure 5: Typical stress vs. strain curves from the standard characterisation tests.

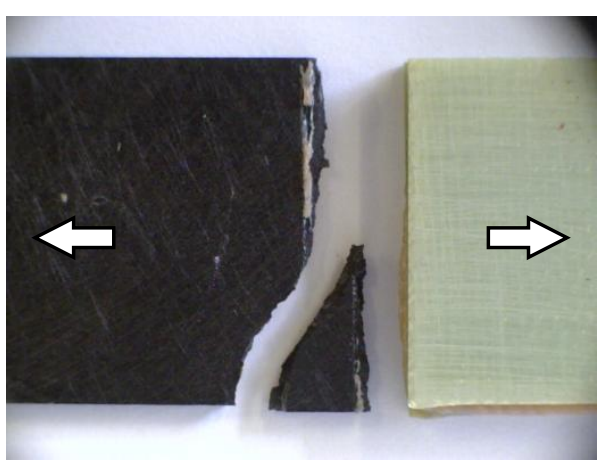

(a) Long. tension.

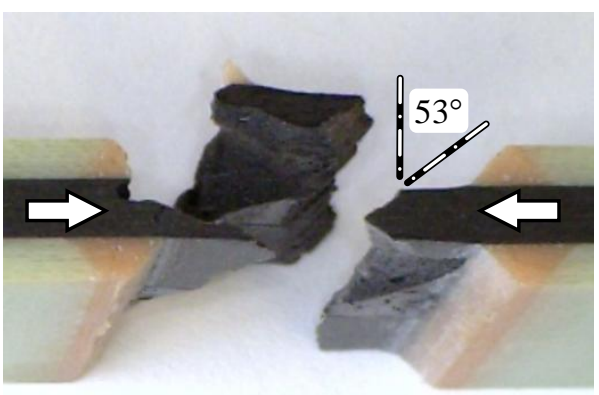

(c) Compression.

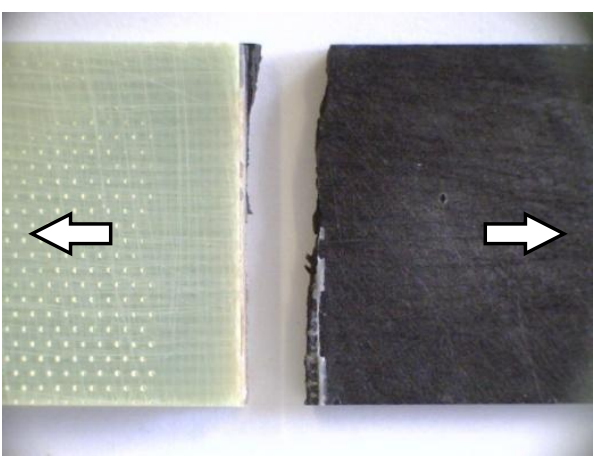

(b) Transv. tension.

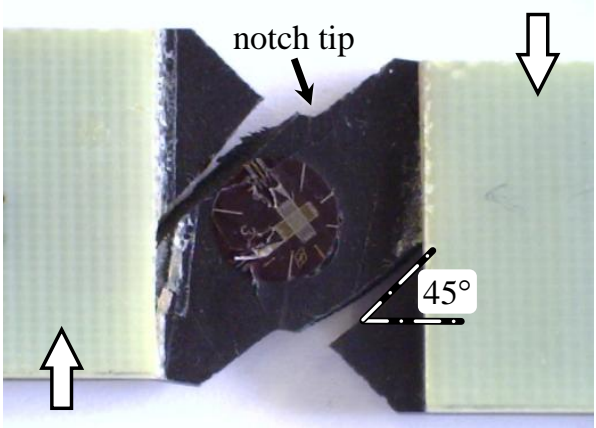

(d) In-plane shear.

Figure 6: Typical failure modes of standard characterisation specimens (wide white arrows represent the loading direction). 
Fig. 8; $G_{\mathrm{T}}$ increased smoothly during each stage of stable propagation (solid branches, for which $\mathcal{G}_{\mathrm{T}}=G_{\mathrm{T}}$ ), and decreased suddenly during the unstable stages (dashed branches).

Table 7 summarises the quantitative results from the CT tests, including: the tensile fracture toughness for initiation $\left(\mathcal{G}_{\mathrm{T}}^{\mathrm{i}}\right)$, the lower and upper limits of fracture toughness within each stable stage (respectively $\mathcal{G}_{\mathrm{T}}^{\text {low }}$ and $\mathcal{G}_{\mathrm{T}}^{\text {up }}$ ), and the variation of toughness during the stable stages $\left(\Delta \mathcal{G}_{\mathrm{T}}^{\text {stbl }}\right)$.

After the tests, fibre-bundles were observed at the specimens' fracture surfaces (Fig. 7); these bundles were either pulled-out from the material (zoom-in I) or defibrillated and broken (zoom-in II). A good correlation was found between the location of larger bundles and the areas of stable propagation (see $G_{\mathrm{T}}(\Delta a)$ curve and the specimen's fracture surface in Fig.7).
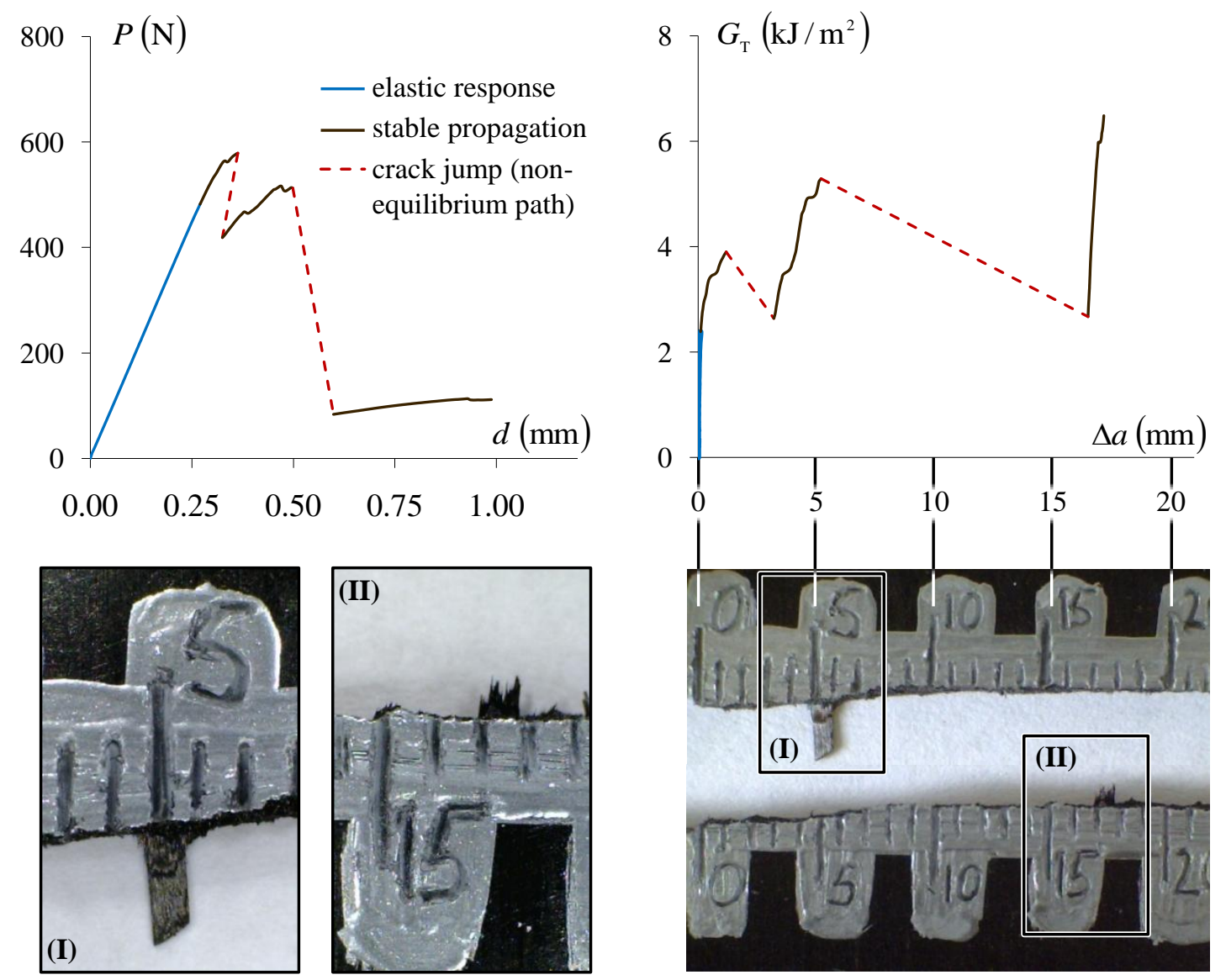

Figure 7: Crack propagation in a typical fracture toughness specimen (GT1\#4): top: $P(d)$ and $G_{\mathrm{T}}(\Delta a)$ data curves (stages of response highlighted); bottom: fracture surfaces - correspondence with $G_{\mathrm{T}}(\Delta a)$ (right) and magnified details (left). 


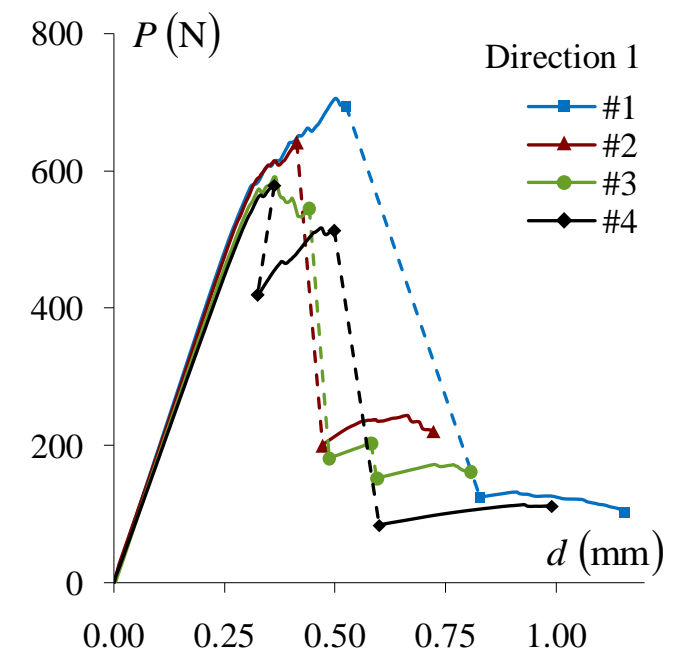

(a) $P$ vs. $d$ curves (direction 1$)$.

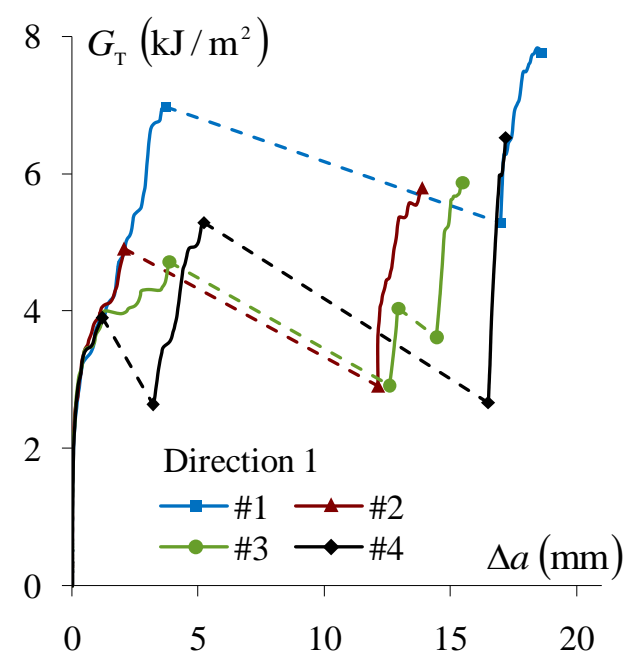

(c) $G_{\mathrm{T}}$ vs. $\Delta a$ curves (direction 1$)$.

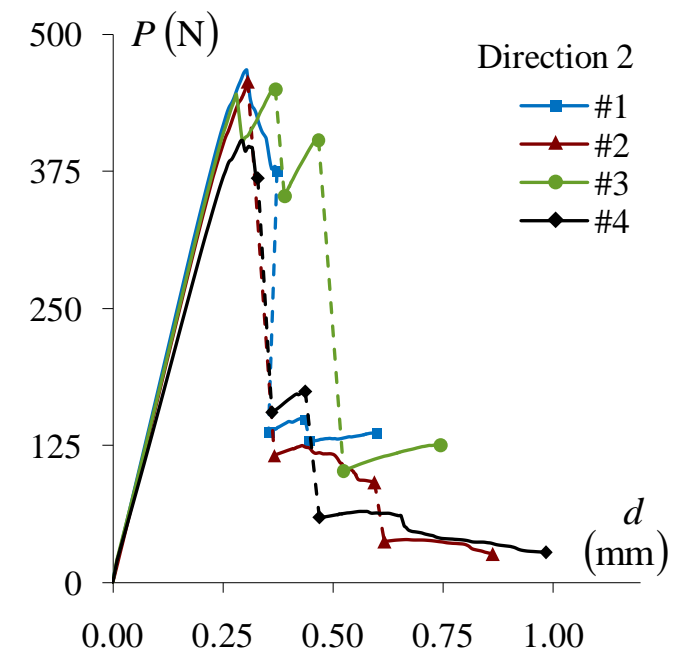

(b) $P$ vs. $d$ curves (direction 2).

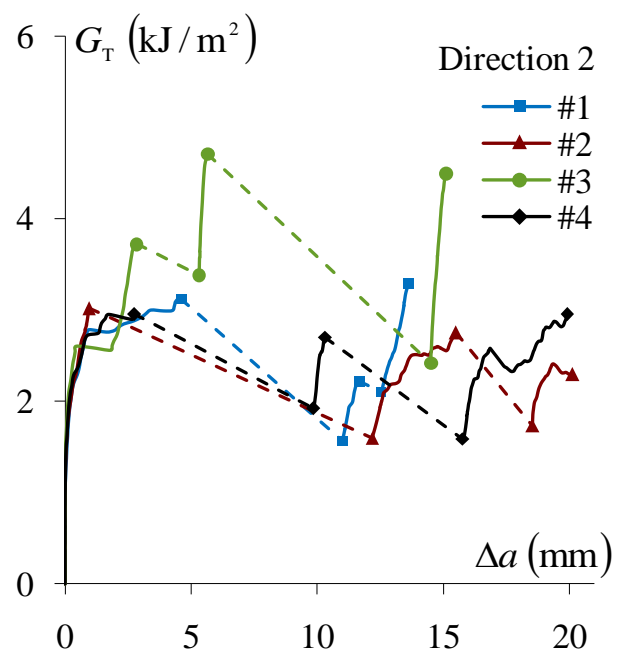

(d) $G_{\mathrm{T}}$ vs. $\Delta a$ curves (direction 2).

Figure 8: All $P(d)$ and $G_{\mathrm{T}}(\Delta a)$ curves from the tensile fracture toughness tests.

Table 7: Summary of the tensile fracture toughness measurements $\left(\mathrm{kJ} / \mathrm{m}^{2}\right)$.

\begin{tabular}{cccccc}
\hline \hline Direction & Property & $\mathcal{G}_{\mathrm{T}}^{\mathrm{i}}$ & $\mathcal{G}_{\mathrm{T}}^{\text {low }}$ & $\mathcal{G}_{\mathrm{T}}^{\text {up }}$ & $\Delta \mathcal{G}_{\mathrm{T}}^{\text {stbl }}$ \\
\hline \multirow{2}{*}{ Long. (1) } & Average & 2.43 & $2.79^{(\mathrm{a})}$ & 5.58 & 2.54 \\
& $\mathrm{CoV}$ & $3.2 \%$ & $5.4 \%{ }^{(\mathrm{a})}$ & $22.5 \%$ & $35.1 \%$ \\
\hline \multirow{2}{*}{ Trans. (2) } & Average & 1.71 & $1.85^{(\mathrm{b})}$ & 3.17 & 1.12 \\
& $\mathrm{CoV}$ & $7.5 \%$ & $17.4 \%^{(\mathrm{b})}$ & $24.4 \%$ & $43.7 \%$ \\
\hline \hline
\end{tabular}

(a) Excludes anomalous values (spec.\#1@ $\Delta a=17.0 \mathrm{~mm}$; spec. \#3@ $\Delta a=14.4 \mathrm{~mm}$ ).

(b) Excludes anomalous values (spec.\#3@ $\Delta a=5.3 \mathrm{~mm}$ ). 


\subsection{Compressive fracture toughness}

All CC specimens failed in a two-stages process: (i) firstly, a thin damage band inclined through-the-thickness propagated stably over $\Delta a \approx 1 \mathrm{~mm}$ to $3 \mathrm{~mm}$; (ii) then, a tensile crack propagated suddenly from the back of the specimen (Fig. 9(a)). A typical load $P$ vs. displacement $d_{\text {extens }}$ curve is shown in Fig. $9(\mathrm{~b})$; the onset of damage is highlighted. The results of fracture toughness for damage initiation under longitudinal compression $\left(\mathcal{G}_{\mathrm{C}}^{1, \mathrm{i}}\right)$ are summarised in Table 8.

\subsection{Failure and toughening mechanisms}

\subsubsection{Tensile mode}

Fig. 10 presents typical in-plane OM images of $\mu$ T specimens, while loaded. During stable crack propagation, failure followed:

(I) The fibre-matrix interface;

(II) Previously-fractured fibre-sections (formed during compression moulding, as mentioned in Section 4.1), with no observed failure of previously undamaged fibresections. This is evidenced by the undamaged state of the matrix ahead of the

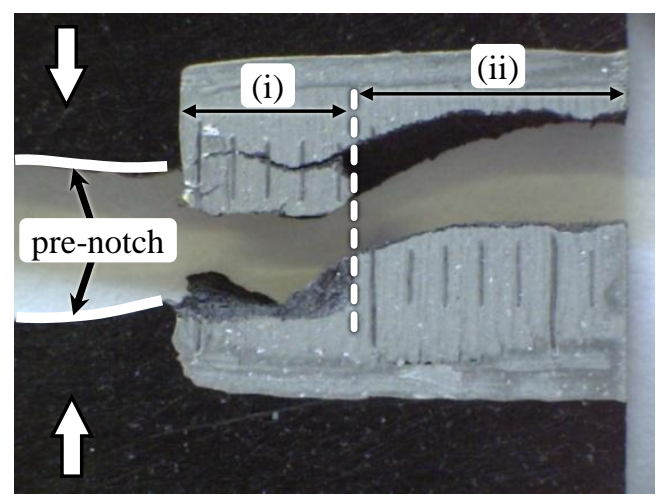

(a) Failed CC specimen (large arrows represent the loading direction):

(i) progressive compressive damage;

(ii) catastrophic tensile failure.

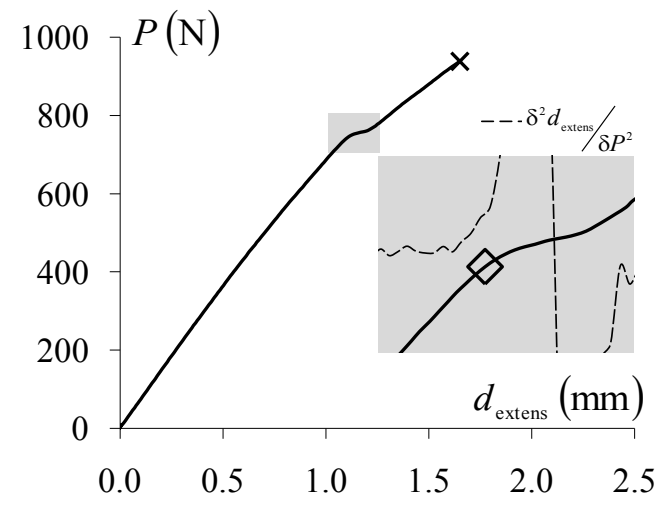

(b) $P$ vs. $d_{\text {extens }}$ curve superposed with $\delta d_{\text {extens }}^{2} / \delta P^{2}$ vs. $d_{\text {extens }}$ :

$\diamond$ : onset of compressive damage;

$x$ : catastrophic tensile failure.

Figure 9: Typical result from the longitudinal compressive toughness tests.

Table 8: Initiation fracture toughness for longitudinal compression.

\begin{tabular}{cc}
\hline \hline Property & $\mathcal{G}_{\mathrm{C}}^{1, \mathrm{i}}\left(\mathrm{kJ} / \mathrm{m}^{2}\right)$ \\
\hline Average & 21.89 \\
CoV & $16.5 \%$ \\
\hline \hline
\end{tabular}


fractured fibre-section in Fig. 10(a), together with the occurrence of extensive fibre breakage during manufacture (Fig. 4(b)).

A typical unstable-fracture surface of a post-mortem tensile specimen (Section 3.2) is shown in Fig. 11; short pulled-out fibres with barely no residual matrix (feature I) were found together with fractured fibre-sections with zero pull-out length (feature II).

The fracture surfaces of the CT specimens show two different morphologies (Fig. 12); by correlating these SEM observations with the $G_{\mathrm{T}}(\Delta a)$ curves (Fig. 8), it was found that stable crack propagation produced rough fracture surfaces with longer fibre pullout (Fig. 12(a)), while unstable crack jumps developed smoother surfaces with shorter pull-out lengths (Fig. 12(b)). Moreover, fibre-bundles were consistently found at the transition between the two morphologies.

The failure mode of fibre-bundles depended on their geometry: thicker bundles were completely pulled-out (Fig. 13(a)) or defibrillated (i.e. failed by splitting and pull-out of fibres within the bundle, Fig. 13(b)); on the contrary, thinner bundles fractured across their section (Fig. 13(c)). Transverse bundles acted as weakening points, promoting initiation and propagation of tensile cracks (Fig. 13(d)).

\subsubsection{Compressive mode}

Under stable compression, the material failed by localised matrix-shearing and fibre-rotation within through-the-thickness shear-bands (Fig. 14 and 15); the first recognisable bands had an inclination of $\beta \approx 20^{\circ}$. With continued compression, the inclination of the shear-band increased progressively, up to a final value of $\beta \approx 54^{\circ}$ (Fig. 14(a)); the deformation of the material inside the band increased as well, which led to the initiation and propagation of a fracture plane within the band (Fig. 14(b)). In subsequent compression stages, complementary shear-bands initiated, propagated and broadened in the specimen (Fig. 14(a)); sharp edges delimiting (almost) undeformed regions from highly deformed shear-bands were observed as well (Fig. 15(b)).

The compressive failure was also affected by the presence of fibre-bundles: Fig. 16 shows a thick bundle, initially aligned with the loading direction, which bent within the shear-band and eventually broke at several cross-sections; this delayed shear-band propagation, diffused the damage, and favoured the formation of large splits. 


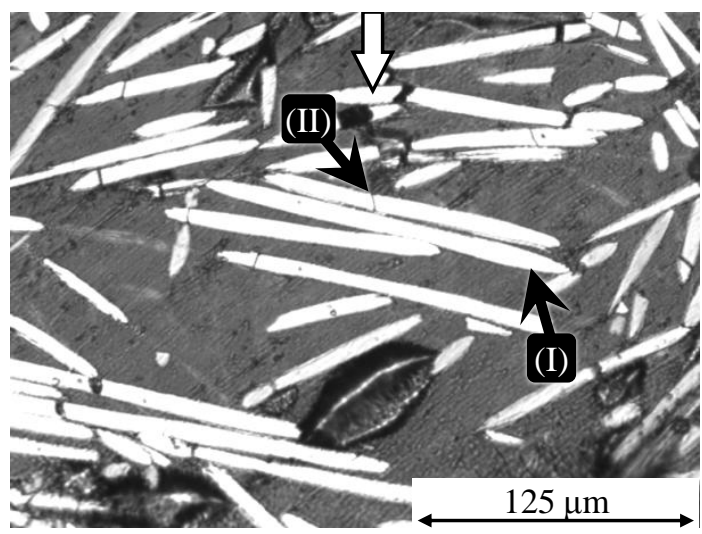

(a) Before crack propagation.

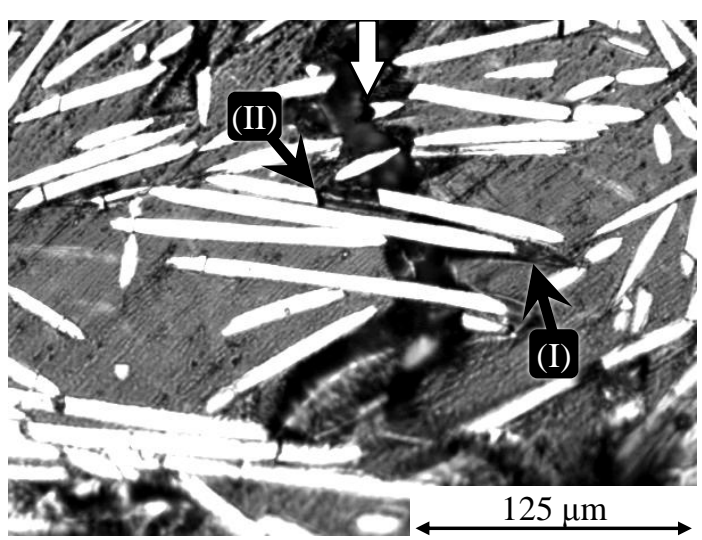

(b) After crack propagation.

Figure 10: Failure mechanisms under stable tensile crack propagation (specimen loaded; wider white arrows represent the macroscopic crack-direction): through (I) fibre-matrix interface and (II) previouslyfractured fibres.

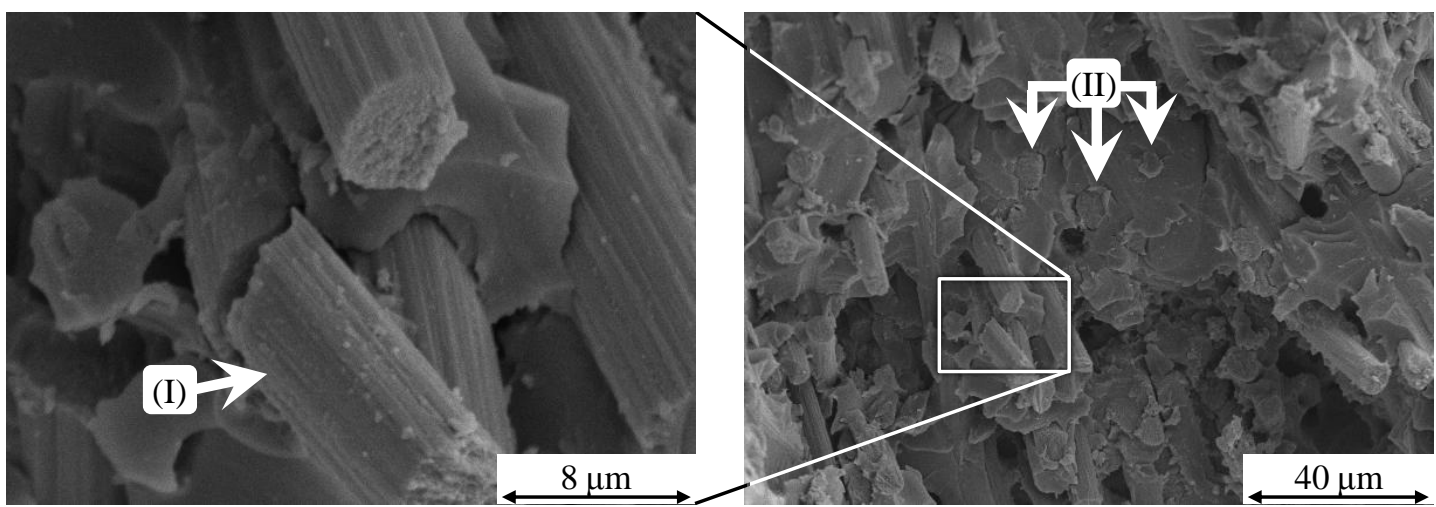

Figure 11: Fracture surface of a post-mortem standard tensile specimen:

(I) pulled-out fibres and (II) fractured fibre-sections.

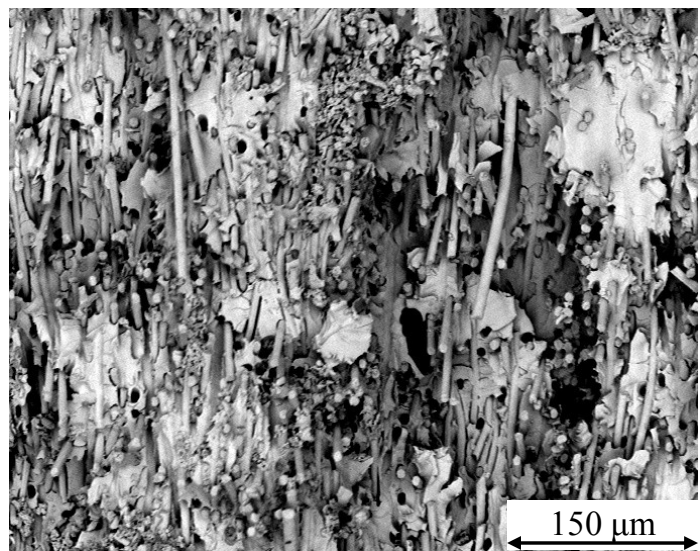

(a) Stable crack propagation.

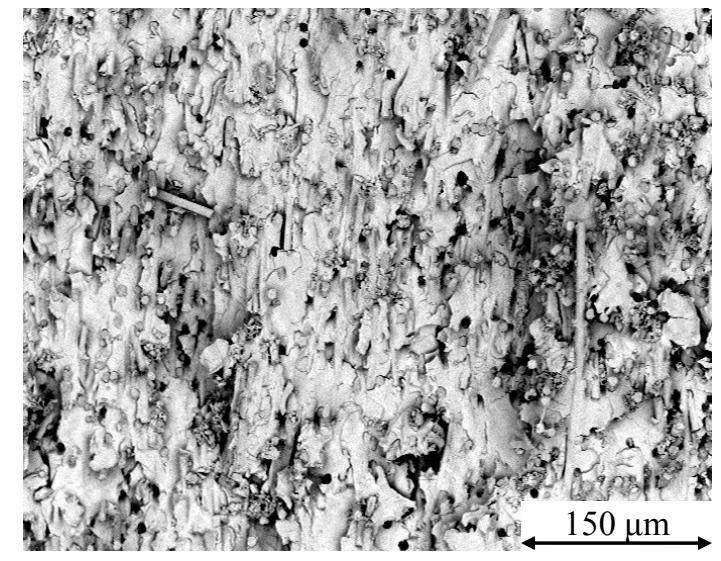

(b) Unstable crack jump.

Figure 12: Typical fracture morphologies in CT specimens. 


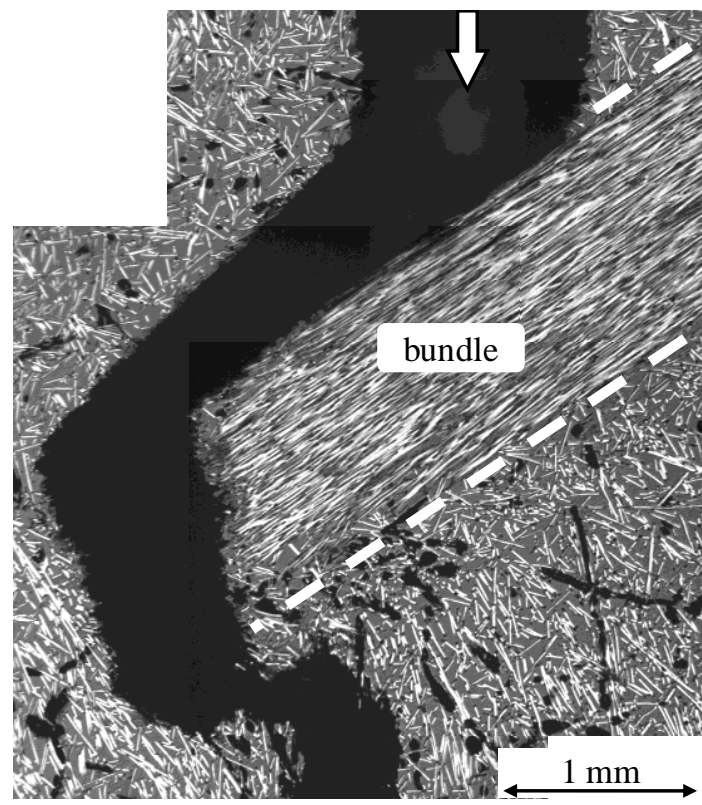

(a) Bundle pull-out.

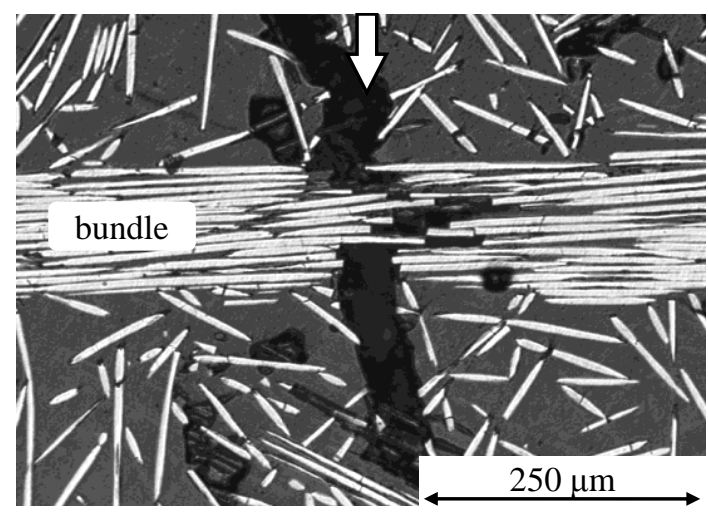

(c) Bundle cross-section failure.

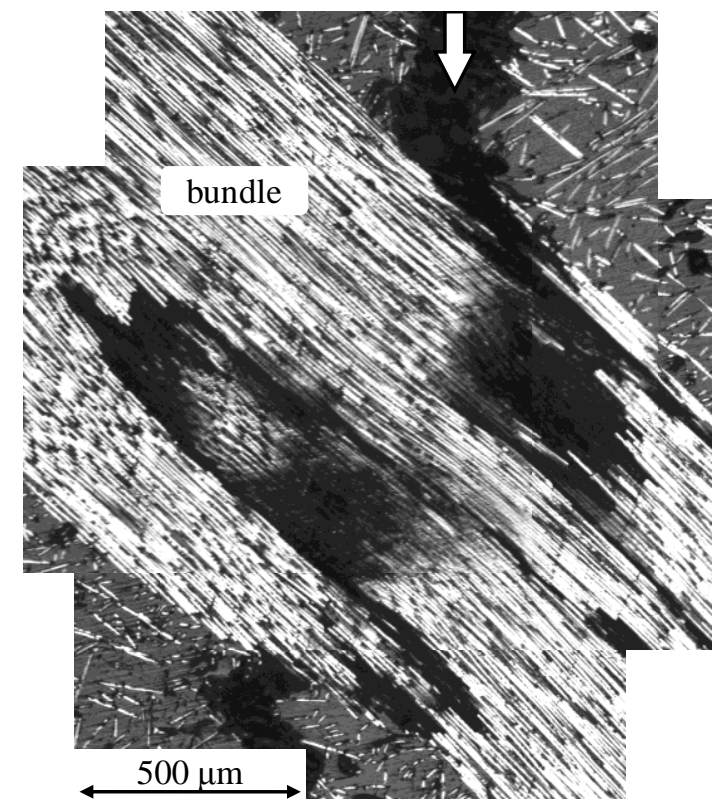

(b) Defibrillation within a bundle.

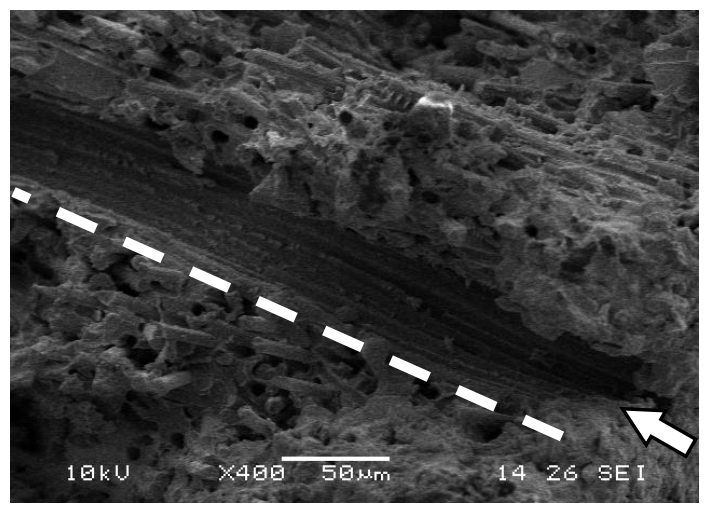

(d) Crack initiation at a transverse bundle.

Figure 13: Failure mechanisms of fibre-bundles under tension (wider white arrows represent the macroscopic crack-direction). 


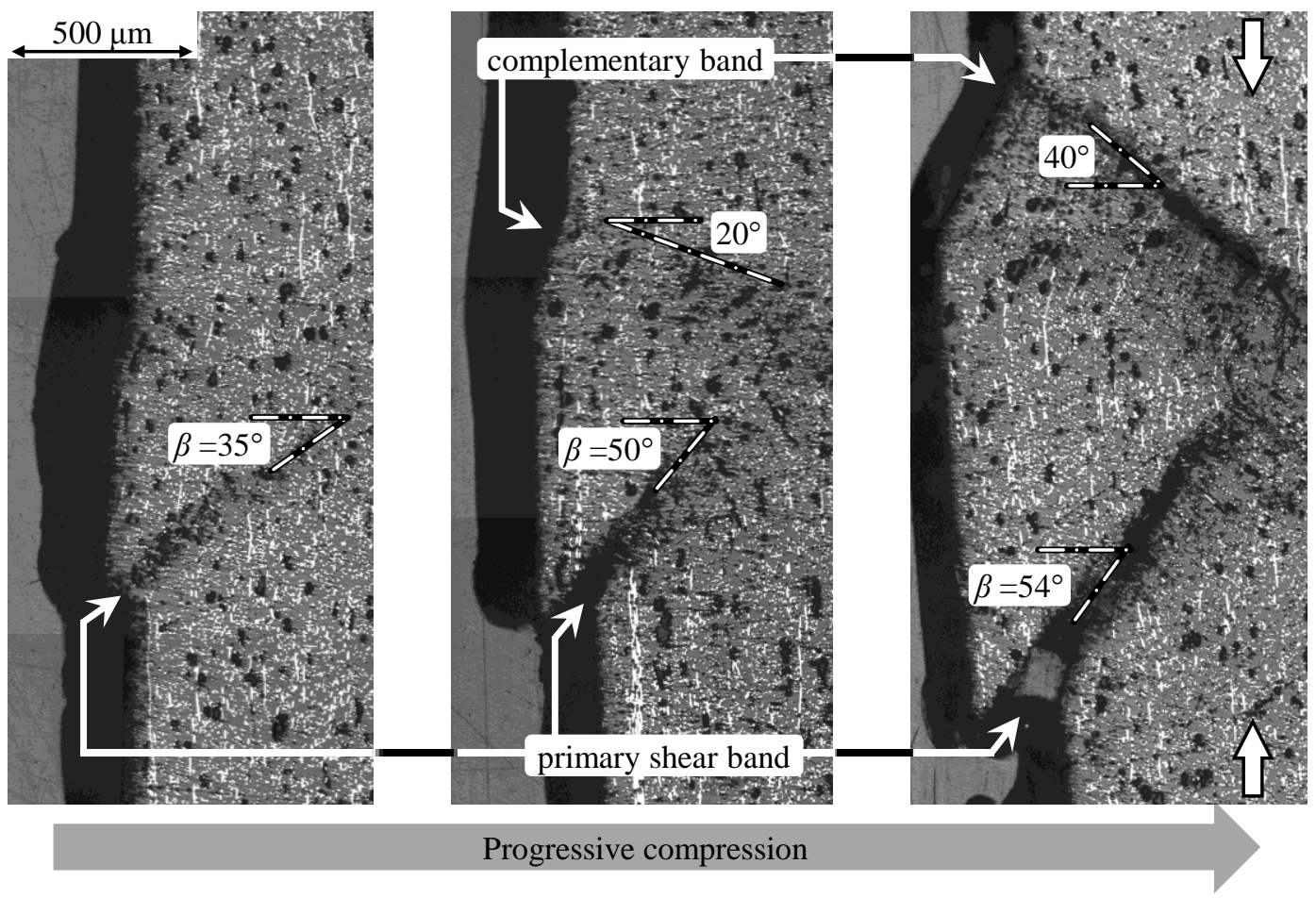

(a) Overall view.
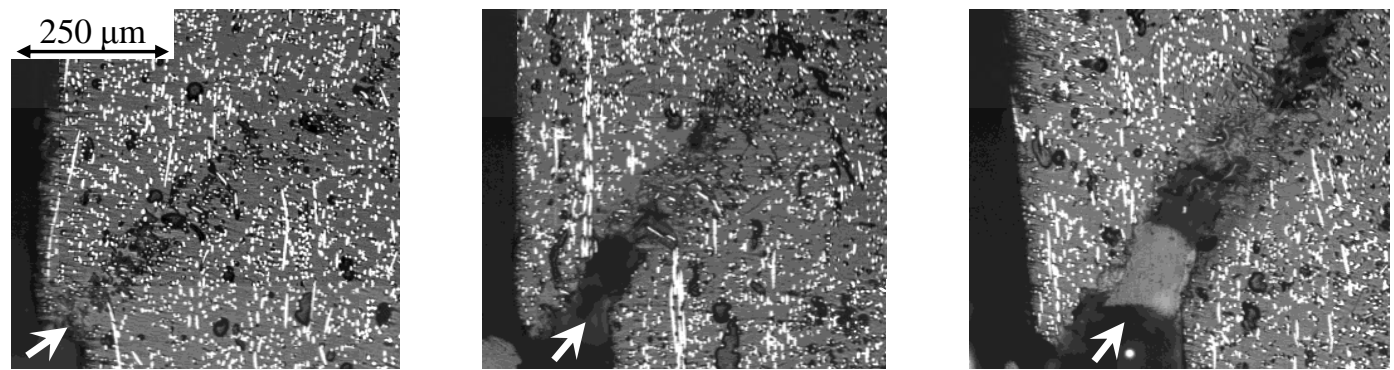

(b) Zoom-in on the primary shear-band.

Figure 14: Sequence of events for stable compressive failure (wider white arrows represent the loading direction). 


\section{Discussion}

\subsection{Role of the critical fibre length on tensile failure}

Tensile failure was strain dominated $\left(e_{\mathrm{T}}^{1} \approx e_{\mathrm{T}}^{2}\right.$, Table 6$)$, which suggests that the fibres failed by pull-out rather than at their cross-section; this was confirmed by OM and SEM observations (Section 4.5.1).

It has been shown that the extremely high moulding pressures required to manufacture rCFRPs with high fibre contents lead to a severe fibre breakage during compression

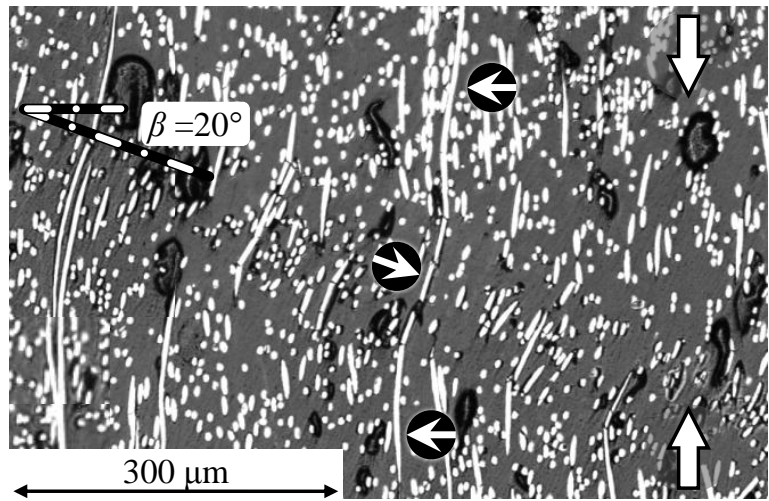

(a) Fibre-rotation within the band.

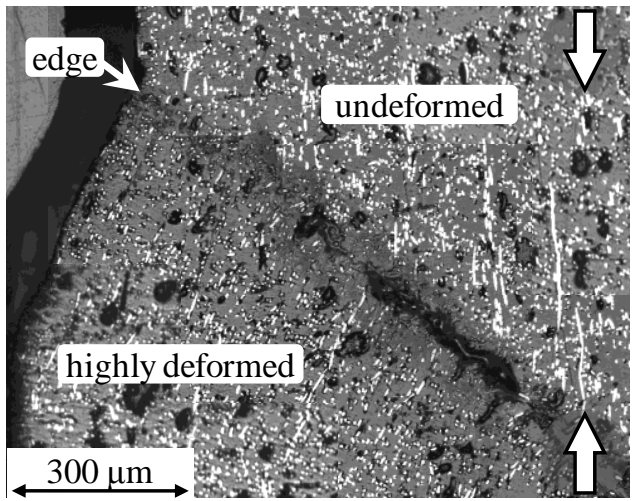

(b) Sharp edge of a shear-band.

Figure 15: Features in compressive shear-bands (wider white arrows represent the loading direction).

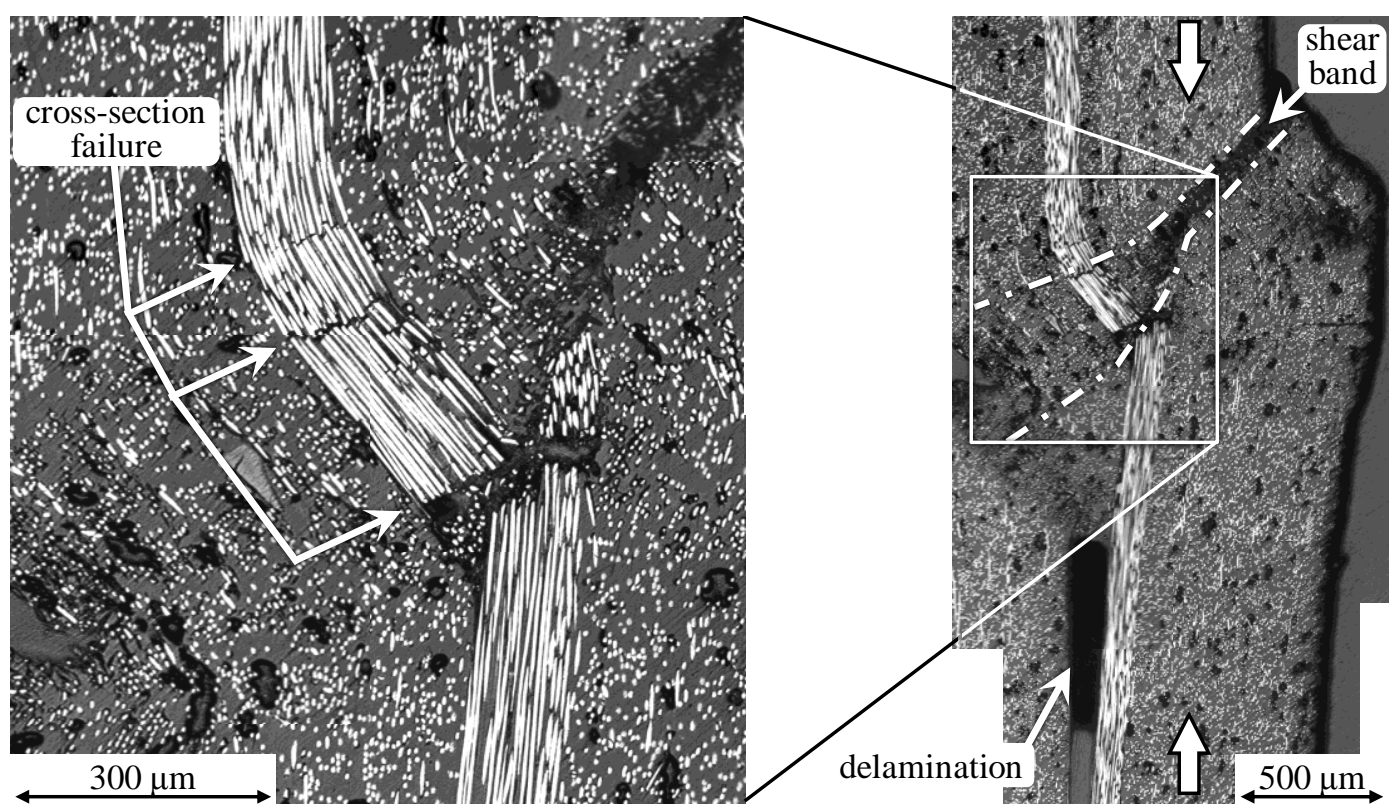

Figure 16: Compressive failure in a region with a thick fibre-bundle (wider white arrows represent the loading direction). 
moulding, which degrades fibre length considerably [11]. From the tensile strength of the $\mathrm{rCF}$ and their interfacial strength with the epoxy matrix, the critical fibre-length in the $\mathrm{rCFRP}\left(l_{\text {crit }}\right)$ comes as:

$$
l_{\mathrm{crit}}=\frac{X_{\mathrm{T}}^{\mathrm{f}} \cdot \phi^{\mathrm{f}}}{2 \cdot S_{\mathrm{IF}}} \Rightarrow l_{\mathrm{crit}} \approx 172 \mu \mathrm{m}
$$

Comparing this value with the composite's expected fibre length distribution (measured at the University of Nottingham for a similar rCFRP [11], which differed from the one analysed in this paper only in the formulation of the epoxy resin), fewer than $40 \%$ of the fibres in the composite are longer than the critical length. Since a good fibre-matrix adhesion was found in the recycled composite (Table 1), this fibre-length degradation during manufacture explains why no fibre failure was observed during stable crack propagation, and it also contributes to justify the low tensile strengths of the recyclate (Table 5 ).

\subsection{Stable vs. unstable tensile failure}

Stable tensile failure of the dispersed-phase occurs preferentially by fibre pull-out (with high energy absorption) and opening of previously-fractured fibre-sections. Little fibre-failure takes place due to the tensile loading (Fig. 11 and 12(a)).

On the contrary, unstable crack jumps produces fibres with smaller pull-out lengths, and a smoother fracture-surface (Fig. 11 and 12(b)). This suggests that previouslyundamaged fibre-sections actually fail during unstable tensile propagation, so fibre pull-out is reduced.

These differences between stable and unstable tensile failure are likely due to a ratedependent response of the matrix (which becomes more brittle as the crack growth rate increases); together with the failure of fibre-bundles, this justifies the higher fracture toughness measured during stable propagation than during the unstable stages (Fig. 8 and Table 7).

\subsection{Influence of fibre-bundles on the tensile fracture toughness}

From the CT testing results (Fig. 7, 8 and 12, and Table 7), the following sequence of events for tensile failure of notched specimens is suggested:

i) A crack initiates from the notch and propagates stably within the dispersed phase;

ii) Fibre bundles ahead of the crack tip increase the local fracture toughness, as they are slowly pulled-out or defibrillated during crack growth; 
iii) After crack propagation through a thick bundle, the energy release rate in the specimen is higher than the fracture toughness of the dispersed-phase; this causes an unstable crack jump, until the elastic energy in the specimen is released and a new fibre-bundle eventually arrests the crack;

iv) The new bundle stabilises crack propagation, and the local fracture toughness increases again as in (i). The sequence of stable vs. unstable propagation is repeated as the crack meets and passes new bundles.

The tensile fracture toughnesses of the dispersed phase can be estimated from $\mathcal{G}_{\mathrm{T}}^{\text {low }}$, as these values are consistent amongst specimens (Table 7 ); this results in $\mathcal{G}_{\mathrm{T}}^{1, \text { disp }} \approx 2.79 \mathrm{~kJ} / \mathrm{m}^{2}$ and $\mathcal{G}_{\mathrm{T}}^{2 \text {,disp }} \approx 1.85 \mathrm{~kJ} / \mathrm{m}^{2}$, one order of magnitude tougher than unreinforced epoxy or transverse UD vCFRPs [22]. Moreover, depending on their geometry, location and orientation, fibre-bundles increased the local fracture toughness of the rCFRP up to 3 times, relatively to the dispersed-phase (Table 7); this is consistent with previous research on virgin Short-Fibre Reinforced Polymers (SFRPs) [24-26].

\subsection{Tensile failure of fibre-bundles}

Under tension, several fibre-bundles failed by clean bundle pull-out (Fig 13(a)) or cross-section fracture (Fig 13(c)); these failure modes can be modelled considering bundles as large-diameter reinforcing-units [24-26]. However, bundle failure by defibrillation was frequent as well (Fig 13(b)); this involves a considerable absorption of energy, which should be taken into account when modelling certain vSFRPs [27] and rCFRPs.

\subsection{Multiscale and fractal features}

The rCFRP has a multiscale microstructure, with $1 \mathrm{~mm}$ wide fibre-bundles and $7 \mu \mathrm{m}$ wide filaments (Fig. 4(a)). Similar pull-out mechanisms were observed at both scales, although individual-filaments and bundles are two order of magnitude apart in dimension (Fig. 17).

In addition, the fracture surface of defibrillated bundles presents itself a fractal pattern. Fig. 18 shows a representative area of the fracture contour (highlighted in dashed red lines) within a bundle, at three different magnification levels. It can be observed that the width-to-length ratios of the pulled-out fibres and bundles are statistically constant amongst the three scales presented, suggesting self-similarity in the pull-out process and formation of fracture surfaces. 


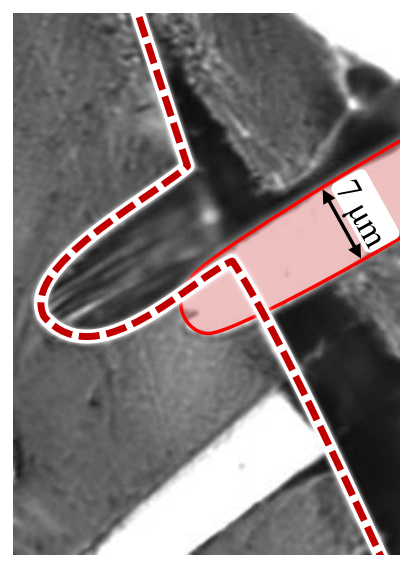

(a) Individual fibre.

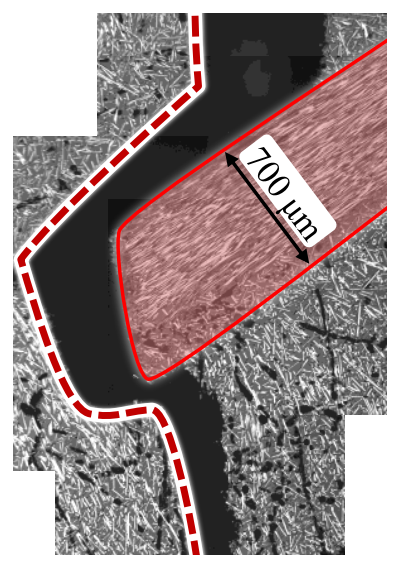

(b) Fibre bundle.

Figure 17: Multiscale similarity of pull-out failure.

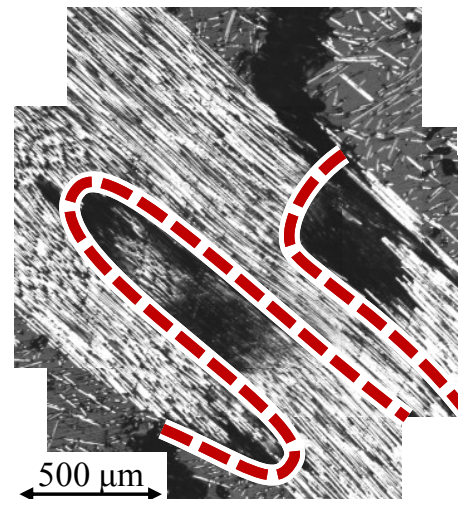

(a) Baseline magnification.

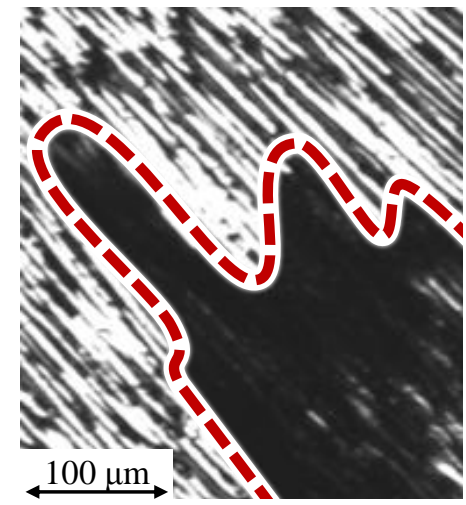

(b) $5 \times$ baseline magnif.

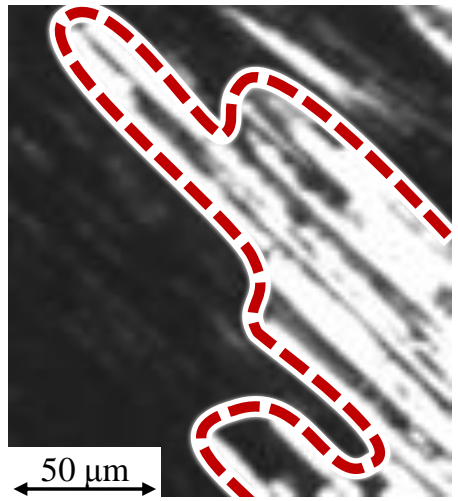

(c) $10 \times$ baseline magnif.

Figure 18: Fractal pattern of defibrillation within a fibre bundle.

\subsection{Compressive failure mode}

Under stable compression, the rCFRP failed by localised shearing. This is one of the most typical failure modes in compression, reported for many different types of material [28-30].

The compressive failure of the rCFRP presents interesting similarities with, on the one hand, fibre kinking, and, on the other, transverse compressive failure of UD CFRPs. As in fibre kinking [31-33], (i) the fibres rotate within the shear bands (Fig. 15(a)); (ii) the bands initiate at low angles $\left(\beta \approx 20^{\circ}\right.$, Fig. 15(a)), which increase with continued compression (Fig. 14); (iii) in some cases, the band broadens and sharp edges are defined (Fig. 15(b)). On the other hand, most of the shear-bands evolved into sharp shearcracks, with no visible plastic deformation, inclined at $\beta \approx 54^{\circ}$ (Fig. 14(a)); this is the 
angle commonly reported for transverse compressive failure of UD composites [30, 34].

The formation of shear bands suggests that matrix yielding plays an important role in the process; this is also the case for fibre kinking [31, 35] and transverse compressive failure of UD composites [30,34]. However, were the compressive failure of the rCFRP a simple shearing mechanism, one would not expect the small band angles $\left(\beta \approx 20^{\circ} \ll\right.$ $45^{\circ}$ ) observed at early stages of damage (Fig. 15(a)). The cause of this behaviour is either (i) an interaction between fibres and matrix, or (ii) a more complex phenomenon intrinsic of epoxy failure.

\subsection{Compressive fracture toughness}

The rCFRP is considerably tougher under compression than under tension $\left(\mathcal{G}_{\mathrm{C}}^{1, \mathrm{i}} \approx 22 \mathrm{~kJ} / \mathrm{m}^{2}\right.$ vs. $\mathcal{G}_{\mathrm{T}} \leq 8 \mathrm{~kJ} / \mathrm{m}^{2}$, Tables 7 and 8 ); this is justified by the higher strength and ductility of the material under compression than in tension (Tables 5 and 6). The formation of a diffuse shear-band absorbs a great amount of energy (when compared with the sharp tensile-cracking); this effect is enhanced by thick bundles aligned with the compressive load, due to damage diffusion and material delamination (Fig. 16).

\subsection{Comparison with virgin materials}

Fig. 19 compares the tensile and compressive specific properties of the rCFRP with those of conventional structural virgin materials — an aerospace grade 2024-T4 Aluminium alloy, and a random short glass-fibre phenolic-resin composite $\left(V^{\mathrm{f}}=31 \%\right)$ typically used in aircraft interiors [12]. The rCFRP performance is close to that of Aluminium, depending on the loading case; this dependence illustrates the need for developing design methods for recyclates. In addition, the rCFRP has superior properties to those of the glass composite, meaning that it could be used in similar applications with significant mass savings.

\subsection{Improvements to the recycling processes}

From the analysis performed, the following directions for improving the fibre-reclamation and rCFRP-manufacturing processes are suggested:

Reducing fibre fracture. Since the presence of longer fibres improves the stiffness, strength and toughness of composites [23], the rCFRP is considerably weakened in tension by the great amount of very short fibres present in the composite. The manufacturers explain this fibre breakage with the high moulding pressures needed to compress the rCF mats with epoxy, due to the filamentised nature of 


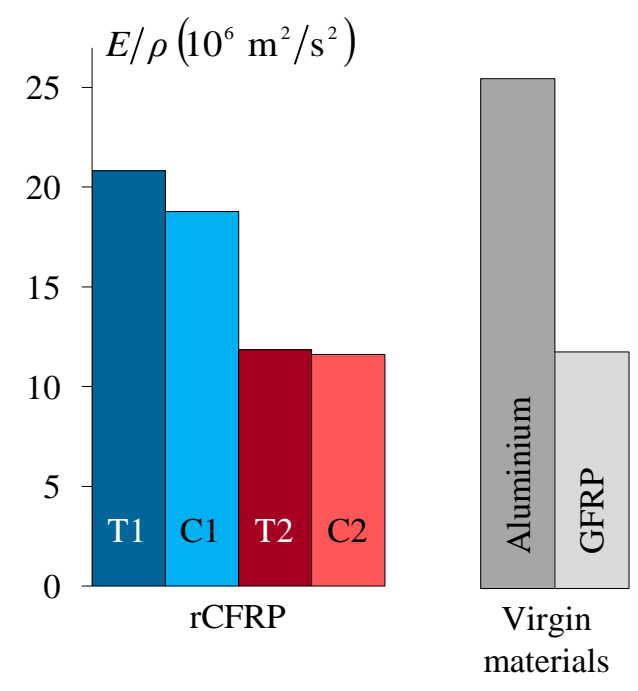

(a) Specific stiffness.

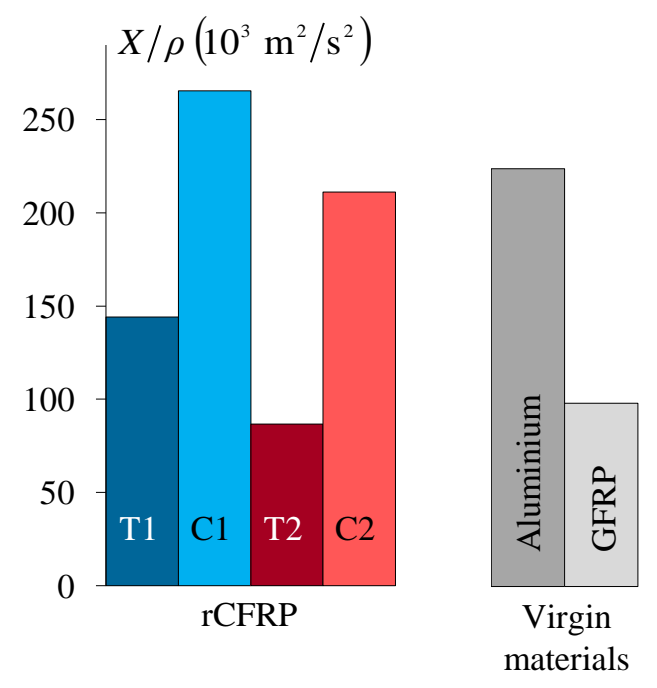

(b) Specific strength.

Figure 19: Mechanical properties of the recycled CFRPs vs. conventional structural virgin materials.

the recycled fibres [11]; this is even more severe in composites with higher fibre contents, which are required for high-end structural applications. Therefore, developing processes for reducing fibre-breakage in manufacture (e.g effective fibrealignment and / or alternative reimpregnation techniques [10, 36, 37]) is critical for the full exploitation of rCFs.

Preserving fibre-bundles. It was shown that fibre-bundles, typically considered as recycling defects, enhance the fracture toughness of the rCFRP considerably. Studies on virgin SFRPs [24-27] support this conclusion; they also suggest that the toughening effect is also achieved when the resin for bundle consolidation is different from the resin in the dispersed phase [26]. Moreover, bundled composites are less susceptible to fibre-fracture during manufacture than individuallydispersed fibres, meaning that higher reinforcement contents can be achieved if bundles are preserved $[23,38]$. Altogether, it is suggested that the optimal recycling process should aim to preserve a controlled amount of fibre bundles, depending on the foreseen application for the recyclate.

\section{Conclusions}

The mechanical response of a state-of-the-art recycled CFRP was investigated experimentally. 
This recycled composite featured fibre-bundles and fractured fibre-sections; this complex and multiscale microstructure was due to both fibre-reclamation and composite-manufacturing processes.

On the overall, the mechanical performance of this rCFRP compared favourably to those of conventional structural materials. The recyclate was nevertheless much stronger under compression than under tension, due to different failure modes under the two loading cases.

Under tension, the material failed by crack propagation following the fibre-matrix interface and the pre-fractured fibre-sections. The fibre breakage occurred during manufacturing was found to reduce over $60 \%$ of the rCFs to sub-critical lengths. The fracture toughness of the recyclate was enhanced by the presence of fibre bundles, due to complex failure mechanisms.

Under compression, the rCFRP initiated shear bands at $\beta \approx 20^{\circ}$; during subsequent loading, complementary shear-bands formed in the composite, and some bands eventually evolved into shear-cracks at $\beta \approx 54^{\circ}$. Interesting similarities between the failure of this recyclate and of UD composites were pointed out.

As a guideline for the recycling process, the importance of avoiding fibre length degradation during compression moulding was stressed; the interest on preserving fibrebundles during pyrolysis and mat-production was highlighted as well.

The experimental analysis here presented focuses on a recycled $C F R P$, and can be used as the foundation for the development of design methods for this type of recyclates. In addition, it also contributes for a better understanding of the mechanical response of several materials, especially the failure mechanisms of SFRPs and the toughening mechanisms of various multiscale materials.

\section{Acknowledgments}

The funding from Portuguese Foundation for Science and Technology (project nr. $\mathrm{SFRH} / \mathrm{BD} / 44051 / 2008)$ is acknowledged.

The authors would like to acknowledge Vishal Hiranandani for taking the optical micrographs of fibre-bundle failure. The authors are also grateful to Dr. A. Bismarck for providing the facilities and guidance for the SFPO tests. The authors would like to thank as well to Mr. S. Alsop, Mr. S. Line and Mr. S. Johnson (from Recycled Carbon Fibre Ltd, UK) for helpful discussions regarding CFRP recycling, and Dr. E.Greenhalgh for his support on the quantitative analysis of the microstructure. 


\section{References}

[1] S. J. Pickering, Recycling technologies for thermoset composite materials - current status, Composites Part A 37 (8) (2006) 1206-1215.

[2] Recycled Carbon Fibre Ltd., www.recycledcarbonfibre.com (last accessed January 2010).

[3] H. L. H. Yip, S. J. Pickering, C. D. Rudd, Characterisation of carbon fibres recycled from scrap composites using fluidised bed process, Plast. Rubber Compos. 31 (6) (2002) 278-282.

[4] L. O. Meyer, K. Schulte, E. Grove-Nielsen, CFRP-recycling following a pyrolysis route: Process optimization and potentials, J. Compos. Mater. 43 (9) (2009) 11211132.

[5] R. E. Allred, J. M. Gosau, J. M. Shoemaker, Recycling process for carbon/epoxy composites, in: SAMPE 2001 Symposium \& Exhibition, SAMPE, Longbeach, CA, USA, 2001.

[6] G. Jiang, S. J. Pickering, et al., Characterisation of carbon fibres recycled from carbon fibre/epoxy resin composites using supercritical n-propanol, Compos. Sci. Technol. 69 (2) (2009) 192-198.

[7] J. P. Heil, M. J. Hall, et al., A comparison of chemical, morphological and mechanical properties of various recycled carbon fibers, in: SAMPE'09 Conference, SAMPE, Baltimore, MD, USA, 2009.

[8] M. L. Connor, Characterization of Recycled Carbon Fibers and Their Formation of Composites Using Injection Molding, Master Thesis, North Carolina State University, Raleigh, NC, USA (2008).

[9] M. A. Janney, W. L. Newell, et al., Manufacturing complex geometry composites with recycled carbon fiber, in: SAMPE'09 Conference, SAMPE, Baltimore, MD, USA, 2009.

[10] T. A. Turner, S. J. Pickering, N. A. Warrior, Development of high value composite materials using recycled carbon fibre, in: SAMPE'09 Conference, SAMPE, Baltimore, MD, USA, 2009.

[11] K. H. Wong, S. J. Pickering, et al., Compression moulding of a recycled carbon fibre reinforced epoxy composite, in: SAMPE'09 Conference, SAMPE, Baltimore, MD, USA, 2009.

[12] K. H. Wong, S. J. Pickering, et al., Preliminary Feasibility Study of Reinforcing Potential of Recycled Carbon Fibre for Flame-retardant Grade Epoxy Composite, in: Composites Innovation 2007, NetComposites, Barcelona, Spain, 2007. 
[13] M. Szpieg, M. Wysocki, L. E. Asp, Reuse of polymer materials and carbon fibres in novel engineering composite materials, Plast. Rubber Compos. 38 (9-10) (2009) 419-425.

[14] S. Pickering, Carbon fibre recycling technologies: what goes in and what comes out?, in: Carbon Fibre Recycling and Reuse, IntertechPira, Hamburg, Germany, 2009.

[15] A. Bismarck, A. Menner, et al., Poly(carbazole-co-acrylamide) electrocoated carbon fibers and their adhesion behavior to an epoxy resin matrix, J. Mater. Sci. 37 (3) (2002) 461-471.

[16] S. G. Advani, C. L. Tucker III, The Use of Tensors to Describe and Predict Fiber Orientation in Short Fiber Composites, Journal of Rheology 31 (8) (1987) 751-784.

[17] R. S. Bay, C. L. Tucker III, Steriological Measurement and Error Estimates for Three-Dimensional Fiber Orientation, Polymer Engineering and Science 32 (4) (1992) 240-253.

[18] University of Texas Health Science Center at San Antonio, Texas, Uthscsa imagetool 2009, ftp: \\maxrad6.uthscsa.edu (last accessed September 2009).

[19] ASTM International, Standard Test Method for Tensile Properties of Polymer Matrix Composite Materials, ASTM D 3039/D 3039M - 07, in: Anual Book of ASTM Standards, Vol. 08, 2008.

[20] J. G. Haberle, E. W. Godwin, The Imperial College Method for Testing Composite Materials in Compression, Technical Memo TM 93/03, The Composites Centre, Imperial College London, UK (1993).

[21] ASTM International, Standard Test Method for Shear Properties of Polymer Matrix Composite Materials by the V-Notched Beam Method, ASTM D 5379/D 5379M-05, in: Anual Book of ASTM Standards, Vol. 08, 2008.

[22] S. T. Pinho, P. Robinson, L. Iannucci, Fracture toughness of the tensile and compressive fibre failure modes in laminated composites, Compos. Sci. Technol. 66 (13) (2006) 2069-2079.

[23] J. Karger-Kocsis, K. Friedrich, Fracture behavior of injection-molded short and long glass fiberpolyamide 6.6 composites, Composites Science and Technology 32 (4) (1988) 293-325.

[24] D. R. Mulligan, S. L. Ogin, et al., Fibre-bundling in a short-fibre composite: 1. review of literature and development of a method for controlling the degree of bundling, Compos. Sci. Technol. 63 (5) (2003) 715-725. 
[25] M. Fila, C. Bredin, M. R. Piggott, Work of fracture of fiber-reinforced polymers, J. Mater. Sci. 7 (9) (1972) 983-988.

[26] J. K. Kim, Y. W. Mai, Fracture of CFRP containing impregnated fiber-bundles, Compos. Sci. Technol. 49 (1) (1993) 51-60.

[27] V. M. Karbhari, D. J. Wilkins, Constituent scale and property effects on fiber matrix debonding and pull-out, J. Mater. Sci. 26 (21) (1991) 5888-5898.

[28] P. Bowden, J. Jukes, Plastic-flow of isotropic polymers, J. Mater. Sci. 7 (1) (1972) 52-63.

[29] C. Schuh, T. Hufnagel, U. Ramamurty, Overview no.144 - mechanical behavior of amorphous alloys, Acta Mater. 55 (12) (2007) 4067-4109.

[30] A. Puck, H. Schurmann, Failure analysis of FRP laminates by means of physically based phenomenological models, Compos. Sci. Technol. 58 (7) (1998) 1045-1067.

[31] P. M. Moran, X. H. Liu, C. F. Shih, Kink band formation and band broadening in fiber composites under compressive loading, Acta Metall. Mater. 43 (8) (1995) 2943-2958.

[32] T. J. Vogler, S. Kyriakides, On the initiation and growth of kink bands in fiber composites: Part I. experiments, Int. J. Solids Struct. 38 (15) (2001) 2639-2651.

[33] S. Pimenta, R. Gutkin, et al., A micromechanical model for kink-band formation: Part I - experimental study and numerical modelling, Compos. Sci. Technol. 69 (78) (2009) 948-955.

[34] S. T. Pinho, L. Iannucci, P. Robinson, Physically-based failure models and criteria for laminated fibre-reinforced composites with emphasis on fibre kinking: Part I: Development, Composites Part A 37 (1) (2006) 63-73.

[35] S. Pimenta, R. Gutkin, et al., A micromechanical model for kink-band formation: Part II - analytical modelling, Compos. Sci. Technol. 69 (7-8) (2009) 956-964.

[36] K. H. Wong, T. A. Turner, et al., The Potential for Fibre Alignment in the Manufacture of Polymer Composites from Recycled Carbon Fibre, in: SAE AeroTech Congress and Exhibition, SAE International, Seattle, Washington, USA, 2009.

[37] K. Friedrich, K. Schulte, G. Horstenkamp, T. W. Chou, Fatigue behaviour of aligned short carbon-fibre reinforced polyimide and polyethersulphone composites, Journal of Materials Science 20 (9) (1985) 3353-3364.

[38] L. T. Harper, T. A. Turner, et al., Characterisation of random carbon fibre composites from a directed fibre preforming process: The effect of tow filamentisation, Composites Part A 38 (3) (2007) 755-770. 